\title{
Risk factor mapping and case map of environmentally based disease in Yogyakarta
}

\author{
Hariza Adnani, ${ }^{1}$ Achmad Arman Subiyanto, ${ }^{2}$ Diffah Hanim, ${ }^{3}$ Endang Sutisna Sulaeman ${ }^{4}$
}

pISSN: 0853-1773 • elSSN: 2252-8083 https://doi.org/10.13181/mji.v28i2.3093 Med J Indones. 2019;28:174-82

Received: August 15, 2018

Accepted: January 28, 2019

\section{Authors' affiliations:}

${ }^{1}$ Graduate Program in Health Promotion and Community Empowerment, Universitas Sebelas Maret, Surakarta, Indonesia, ${ }^{2}$ Masters Program in Family Medicine, Universitas Sebelas Maret, Surakarta, Indonesia, ${ }^{3}$ Master Program in Nutrition, Universitas Sebelas Maret Surakarta, Indonesia, ${ }^{4}$ Master Program in Public Health, Universitas Sebelas Maret, Surakarta, Indonesia

\section{Corresponding author:}

Hariza Adnani

Graduate Program in Health Promotion and Community Empowerment, Universitas Sebelas Maret, Jalan Ir. Sutami Nomor 36 A, Kentingan, Surakarta 57126, Central Java, Indonesia Tel/Fax: +62-271-632450

E-mail: adnani.hariza@yahoo.com

\begin{abstract}
BACKGROUND A geographic information system (GIS) is required to guide interventions into prevent acute respiratory infection (ARI) and reduce the incidence of cases. The purpose of this study is to find out whether there is spatial autocorrelation in the spread of ARI; to obtain spatial information about the ARI risk factors, the ARI case map, and the factors related to the occurrence of ARI.
\end{abstract}

METHODS This study is a quantitative research study with case-control study design. The sampling technique was purposive sampling. Spatial analysis techniques used were buffers and spatial clustering. The measurement of spatial autocorrelation was calculated by Moran's Index method.

RESULTS The risk factors for ARI based on the history of ARI disease were cough and cold in the last one year, and cough and cold lasting more than two weeks (OR = 15.691; $95 \% \mathrm{Cl}=6.558-37.546$ and $\mathrm{OR}=6.645 ; 95 \% \mathrm{Cl}=3.013-14.652$ ). The risk factors for $\mathrm{ARI}$ based on the house physical environment were the room density, existence of glass windows on the house roof, electricity as a light source, presence of family members who smoke, and proximity to pollution exposure and waste disposal. Moran's Index value shows positive spatial autocorrelation.

CONCLUSIONS GIS produces ARI distribution patterns. Based on the results of the cluster, the incidence of ARI cases in this region are interrelated or one case with another case is closely related, due to its close position.

KEYWORDS case study, geographic information system, health risk assessment, infectious diseases, map
Acute respiratory infections (ARIs) are classified as upper respiratory tract infections (URIs) or lower respiratory tract infections. The upper respiratory tract consists of the airways from the nostrils to the vocal cords in the larynx, including the paranasal sinuses and the middle ear. The lower respiratory tract covers the continuation of the airways from the trachea and bronchi to the bronchioles and the alveoli. ARIs are not confined to the respiratory tract and have systemic effects because of the possible extension of infection or microbial toxins, inflammation, and reduced lung function. Diphtheria, pertussis (whooping cough), and measles are vaccine-preventable diseases that may have a respiratory tract component but also affect other systems. ${ }^{1}$ 
ARI is one of the environmental based diseases often founded in developing countries (their mortality rate in toddlers is over 40 of 1,000 live births). Its incidence is $15-20 \%$ per year in toddlers. According to World Health Organization, approximately 13 million toddlers in the world die every year, and ARI is one of the major causes of death by killing 4 million toddlers annually. Indonesia is still burdened with environmentally based communicable diseases, such as dengue hemorrhagic fever, pulmonary tuberculosis (TB), malaria, diarrhea, ARIs, HIV/AIDS, filariasis, worms, skin diseases, poisoning, and health issues because of poor working environments. Based on Riset Kesehatan Dasar (RISKESDAS) in 2013, the number of pneumonia ARI cases tended to increase for the period when the prevalence of pneumonia of all ages rise from $2.1 \%$ in 2007 to $2.7 \%$ in 2013 . The prevalence of pulmonary TB remains in the same position for both 2007 and 2013 at $0.4 \%$. There was an increase in the prevalence of hepatitis in all age groups from $0.6 \%$ in 2007 to $1.2 \%$ in 2013. In contrast, there was a decrease in the period prevalence rate of diarrhea from 9.0\% in 2007 to $3.5 \%$ in $2013 .^{2}$

In Indonesia, Riskesdas in 2013 showed that the period prevalence of ARI based on the diagnosis of health personnel and community complaints was $25 \%$. The incidence and the prevalence of ARI in Indonesia in 2013 were $1.8 \%$ and $4.5 \%$, respectively. ARI risk factors can be divided into two groups: internal and external factors. Internal factors are conditions within the patient (toddler), which makes the individual easier to be exposed to ARI disease agents that include sex, birth weight, breastfeeding status, and immunization status. External factors are conditions that are outside the patient (toddler) in the form of physical, biological, social, and economic environment that make them easier to be exposed to disease agents, including: cigarette smoke pollution, kitchen smoke pollution, density of residence, geographical condition, ventilation of $10 \%$ of the floor area, and lighting. ${ }^{3}$

ARI disease in the working area of Puskesmas Imogiri I was one of the top 10 diseases but was not the most important in both 2016 and 2017. Based on the data of the top 10 diseases at Puskesmas Imogiri I, the most common disease in January-December 2016, was fever of unknown origin (2,400 people or $17.03 \%)$, and the most common disease in the community in
January-May 2017, was dyspepsia (807 people or $16.60 \%)$.

Prevention efforts can also be implemented by knowing the spatial distribution of the patients. Almost all Puskesmas in Bantul Regency process the data of ARI case distribution and ARI risk factors manually and semi-automatically, and their presence is still limited to the forms of tables and graphs. Moreover, there is no presentation in the form of maps. Therefore, a geographic information system (GIS) is required to create risk factor maps, case maps, and other activity maps, which ultimately helps to guide interventions to prevent ARI and reduce the incidence of cases.

Information exposure through a GIS can be used by the Puskesmas to obtain information and provide information for the community regarding the distribution of prone areas. A GIS is one of the health information systems that can generate spatial information about a particular situation so that it can assist in decision-making. Therefore, this research combined information from engineering and health sciences to create a disease map by utilizing the functionality of GIS.

Based on the above explanation, the aim of the study was to create a map of case distribution and risk factors of environment-based disease (ARI) in Bantul District and to find out factors related to ARI risk factors in toddlers. The selected ARI is URI.

\section{METHODS}

This study was a quantitative research study with epidemiologic case-control study design. ${ }^{6}$ The research was conducted in the working area of Puskesmas Imogiri Bantul. It covered four villages: Wukirsari, Imogiri, Karang Talun, and Girirejo. The population was 777 patients who went to Puskesmas Imogiri with complaints of nasopharyngitis ARI. Total sampling was used as the sampling method. There were two groups based on the following criteria: parents whose toddlers suffered from nasopharyngitis (170 toddlers as the case group), and parents whose toddlers were healthy or did not suffer from nasopharyngitis (170 toddlers as the control group).

Spatial analysis was performed to determine the distribution area of ARI. GIS software was used to reveal the exact location and distribution of ARI 
in toddlers. A chi-square test was performed to find out whether there was a correlation between two variables (nominal data), and, if so, its strength. The riskiest variables used an odds ratio (OR). Moran's Index was one of the spatial analysis techniques used to determine the presence of spatial autocorrelation between observation locations. In the significance test, a normal approach was used to determine whether there was a spatial autocorrelation. The value in the calculation of Moran's Index was between -1 and 1, and if the value was 0 , it meant that it was not in the group.

\section{RESULTS}

The distribution of ARI cases in toddlers based on risk factors is shown in Table 1 . It showed that toddlers with a densely occupied room ( $>2$ persons) were more numerous than toddlers with nonoccupancy (1-2 persons). The number of toddlers' rooms with non-permanent floors (not tiled yet) was bigger than that with permanent floors. There were more houses with non-permanent walls than those with permanent walls. There were more toddlers' rooms with bright light than those without bright light. There were more toddlers' rooms without glass windows on the roof than those with glass windows on the roof. The number of houses using electricity as the lighting source was higher than that which did not use electricity as the lighting source. Table 1 also shows that smoke from the kitchen mostly did not go into toddlers' rooms. Most toddlers' family members continued to smoke. Most toddlers' houses were away from highway pollution. Clean water was difficult to access in the ARI group; water reservoirs for daily activities were mostly open. The distance of septic tanks from the clean water source was mostly less than $10 \mathrm{~m}$. Most toddlers' families had an absorbing well. Most toddlers' families did not destroy their garbage even though the garbage dump was typically less than $10 \mathrm{~m}$ from the house.

Table 1 shows the correlation between 15 indicators of house physical environment variables and ARI disease in toddlers. A correlation was seen from the value of Pearson's chi-square $\left(\lambda^{2}\right)$ and the sign values of the room density, house floor type, light entering the house, light source, presence of smoking family members, proximity to pollution exposure, existence of a clean water source, condition of water reservoirs, distance of septic tank to clean water source, waste disposal behavior, sewerage conditions, existence of an absorbing well, and distance between the house and garbage dump. The indicators that did not show a correlation between house physical environment and ARI disease in toddlers were the house walls, existence of glass windows on the house roof, kitchen smoke, and behavior of waste destruction $\left(\lambda^{2}=3.034\right.$ and sign $=0.082, \lambda^{2}=<0.001$ and sign $=0.986, \lambda^{2}=0.204$ and sign $=0.652 ; \lambda^{2}=0.282$ and sign $\left.=0.595\right)$. Seven risk factors increased the incidence of ARI in toddlers: the room occupancy density, glass window on house roof, electricity source, presence of smoking family members, and proximity to both pollution exposure and waste destruction. It was seen from the value of the $\mathrm{OR}$ and confidence interval $(\mathrm{Cl})$ that the lower and upper limits were $>1$. The allegation was made stronger since the room occupancy density, house roof without glass windows, electricity source, presence of smoking family members, proximity to pollution exposure, and not performing waste destruction were risk factors of $A R I$. Ten risk factors reduced the risk of ARI incidence in toddlers. They were having permanent types of floors, permanent walls, lighting, a clean water source, a closed and clean garbage dump, a septic tank at a distance over $10 \mathrm{~m}$, garbage thrown out appropriately, a closed sewage channel, an absorbing well, and the distance between the garbage dump and the clean water source over $10 \mathrm{~m}$.

Table 2 shows the results of physical quality measurements in toddlers' rooms. It shows that the temperature of most toddlers' rooms temperature was unacceptable $\left(<18^{\circ} \mathrm{C}\right.$ or $\left.>30^{\circ} \mathrm{C}\right)$. The humidity of most rooms was good. The light source was mostly less than 60 lux. The room space was mostly $<8 \mathrm{~m}^{2}$ with a ventilation area $\geq 1 / 10$ of the floor area. Table 2 shows that there was a relationship between toddlers' room temperature, humidity of most rooms, light source, room space, and ventilation area with ARI disease in toddlers $\left(\lambda^{2}=19.018\right.$ and sign $=<0.001, \lambda^{2}=29.224$ and sign $=<0.001, \lambda^{2}=74.558$ and sign $=<0.001, \lambda^{2}=12.815$ and sign $=<0.001, \lambda^{2}=46.364$ and sign $=<0.001)$. These five risk factors increased the incidence of $A R I$ in toddlers. It was seen from the values of $\mathrm{OR}$ and $\mathrm{Cl}$ that the lower and upper limits were $>1$. The allegation was made stronger since they were risk factors of ARI.

Table 3 shows the results of the distribution of ARI cases based on the history of ARI. It shows that most coughs, colds in the last one year and lasting under 
two weeks, not exclusively breastfed, and incomplete immunization. It also indicates that there was a relationship between two indicators, the history of ARI and ARI disease, in toddlers in the working area of Puskesmas Imogiri 1 Bantul. This relationship was seen from the value of Pearson chi-square $\left(\lambda^{2}\right)$ and the sign value of cough and cold in the last one year, and lasting over two weeks $\left(\lambda^{2}=57.647\right.$ sign $=<0.001$ and $\lambda^{2}=6.645$ and sign $=<0.001)$. It was seen from the OR and $\mathrm{Cl}$ lower limit and upper limit >1. The allegation was made stronger: since a toddler who had a cough and cold in the last one year and lasting for over two weeks were risk factors for ARI. The indicators that did not relate to the history of ARI were exclusive breastfeeding and immunization completeness $\left(\lambda^{2}=2.116\right.$ sign $=0.146$ and $\lambda^{2}=0.298$ and sign $\left.=0.585\right)$. These two risk factors reduced the risk of $A R I$ in toddlers in the working area of Puskesmas Imogiri Bantul.

Table 1. Distribution of ARI cases based on the physical conditions of the house

\begin{tabular}{|c|c|c|c|c|c|c|}
\hline Physical conditions of the house & $\begin{array}{c}\text { ARI } \\
n(\%),(n=170)\end{array}$ & $\begin{array}{c}\text { No ARI } \\
n(\%),(n=170)\end{array}$ & $\lambda^{2}$ & OR & $95 \% \mathrm{Cl}$ & $p$ \\
\hline \multicolumn{7}{|l|}{ Densely } \\
\hline Yes & $131(77.06)$ & $95(55.88)$ & 17.103 & 2.65 & $1.660-4.236$ & $<0.001$ \\
\hline No & $39(22.94)$ & $75(44.11)$ & & & & \\
\hline \multicolumn{7}{|l|}{ Permanent floor } \\
\hline Yes & $28(16.47)$ & $13(7.64)$ & 6.240 & 0.420 & $0.209-0.842$ & 0.012 \\
\hline No & $142(83.53)$ & $157(92.35)$ & & & & \\
\hline \multicolumn{7}{|l|}{ Permanent walls } \\
\hline Yes & $12(7.06)$ & $5(2.94)$ & 3.034 & 0.399 & $0.137-1.158$ & 0.082 \\
\hline No & $158(92.94)$ & $165(97.05)$ & & & & \\
\hline \multicolumn{7}{|l|}{ Bright light } \\
\hline Yes & $126(74.12)$ & $159(93.53)$ & 23.62 & 0.198 & $0.098-0.399$ & $<0.001$ \\
\hline No & $44(25.88)$ & $11(6.47)$ & & & & \\
\hline \multicolumn{7}{|l|}{ Glass windows on roof } \\
\hline Yes & $17(10)$ & $17(10)$ & 0.986 & 1.007 & $0.496-2.045$ & $<0.001$ \\
\hline No & $153(90)$ & $152(89.41)$ & & & & \\
\hline \multicolumn{7}{|l|}{ Light source } \\
\hline Yes & $6(3.53)$ & $0(0)$ & 6.108 & 2.037 & $1.826-2.272$ & 0.013 \\
\hline No & $164(96.47)$ & $170(100)$ & & & & \\
\hline \multicolumn{7}{|l|}{ Smoke from kitchen } \\
\hline Yes & $49(28.82)$ & $45(26.47)$ & 0.204 & 1.116 & $0.693-1.796$ & 0.652 \\
\hline No & $121(71.18)$ & $124(72.94)$ & & & & \\
\hline \multicolumn{7}{|l|}{ Family smokes } \\
\hline Yes & $117(68.82)$ & $76(44.70)$ & 20.145 & 2.730 & $1.752-4.255$ & $<0.001$ \\
\hline No & $53(31.18)$ & 94 (55.29) & & & & \\
\hline \multicolumn{7}{|l|}{ Highway pollution } \\
\hline Yes & $65(38.24)$ & $34(20)$ & 13.695 & 2.476 & $1.522-4.029$ & $<0.001$ \\
\hline No & $105(61.76)$ & $136(80)$ & & & & \\
\hline \multicolumn{7}{|l|}{ Clean water } \\
\hline Easy & $8(4.71)$ & $1(0.59)$ & 5.592 & 0.120 & $0.015-0.969$ & 0.018 \\
\hline Difficult & $162(95.29)$ & $169(99.41)$ & & & & \\
\hline \multicolumn{7}{|l|}{ Closed water reservoirs } \\
\hline Yes & $59(34.71)$ & $15(8.82)$ & 33.440 & 0.182 & $0.098-0.337$ & $<0.001$ \\
\hline No & $111(65.29)$ & $155(91.17)$ & & & & \\
\hline \multicolumn{7}{|l|}{ Distance of septic tank $\geq 10 \mathrm{~m}$} \\
\hline Yes & $42(24.71)$ & $18(10.59)$ & 11.657 & 0.361 & $0.198-0.658$ & 0.001 \\
\hline No & $128(75.29)$ & $152(89.41)$ & & & & \\
\hline
\end{tabular}


Table 1. (Continued)

\begin{tabular}{|c|c|c|c|c|c|c|}
\hline Physical conditions of the house & $\begin{array}{c}\text { ARI } \\
n(\%),(n=170)\end{array}$ & $\begin{array}{c}\text { No ARI } \\
n(\%),(n=170)\end{array}$ & $\lambda^{2}$ & OR & $95 \% \mathrm{Cl}$ & $p$ \\
\hline \multicolumn{7}{|l|}{ Garbage disposal } \\
\hline Yes & $34(20)$ & $38(22.35)$ & 0.282 & 1.152 & $0.684-1.939$ & 0.595 \\
\hline No & $136(80)$ & $132(77.64)$ & & & & \\
\hline \multicolumn{7}{|l|}{ Infiltration wells } \\
\hline Yes & $72(42.35)$ & $34(20)$ & 19.794 & 0.340 & $0.210-0.552$ & $<0.001$ \\
\hline No & $98(57.65)$ & $136(80)$ & & & & \\
\hline \multicolumn{7}{|l|}{ Distance of garbage dump $\geq 10 \mathrm{~m}$} \\
\hline Yes & $64(37.65)$ & $13(7.64)$ & 43.669 & 0.137 & $0.072-0.261$ & $<0.001$ \\
\hline No & $106(62.35)$ & $157(92.35)$ & & & & \\
\hline
\end{tabular}

$A R=$ acute respiratory infection; $O R=$ odds ratio; $\mathrm{Cl}=$ confidence interval

Table 2. Distribution of ARI cases based on physical quality measurements in toddlers' rooms

\begin{tabular}{|c|c|c|c|c|c|c|}
\hline & $\begin{array}{c}\text { ARI } \\
n(\%),(n=170)\end{array}$ & $\begin{array}{c}\text { No ARI } \\
n(\%),(n=170)\end{array}$ & $\lambda^{2}$ & OR & $95 \% \mathrm{Cl}$ & $p$ \\
\hline \multicolumn{7}{|c|}{ Room temperature $\left({ }^{\circ} \mathrm{C}\right)$} \\
\hline $18-30$ & $10(5.88)$ & $38(22.35)$ & 19.018 & 4.606 & $2.211-9.594$ & $<0.001$ \\
\hline$<18$ or $>30$ & $160(94.11)$ & $132(77.65)$ & & & & \\
\hline \multicolumn{7}{|c|}{ Relative humidity (RH), (\%) } \\
\hline $40-60$ & $121(71.18)$ & $159(93.53)$ & 29.224 & 5.853 & $2.920-11.733$ & $<0.001$ \\
\hline$<40$ or $>60$ & $49(28.82)$ & $11(6.47)$ & & & & \\
\hline \multicolumn{7}{|c|}{ Light source (lux) } \\
\hline$\geq 60$ & 19 (11.17) & 94 (55.29) & 74.558 & 9.830 & $5.588-17.292$ & $<0.001$ \\
\hline$<60$ & $151(88.82)$ & $76(44.71)$ & & & & \\
\hline \multicolumn{7}{|c|}{ Ventilation area (floor area) } \\
\hline$\geq 1 / 10$ & $116(68.24)$ & $144(84.71)$ & 12.815 & 2.578 & $1.521-4.371$ & $<0.001$ \\
\hline$<1 / 10$ & $54(31.76)$ & $26(15.29)$ & & & & \\
\hline \multicolumn{7}{|c|}{ Room space $\left(m^{2}\right)$} \\
\hline$\geq 8$ & $80(47.06)$ & $140(82.35)$ & 46.364 & 5.250 & $3.196-8.623$ & $<0.001$ \\
\hline$<8$ & $90(52.94)$ & $30(17.65)$ & & & & \\
\hline
\end{tabular}

$\mathrm{ARI}=$ acute respiratory infection; $\mathrm{OR}=$ odds ratio; $\mathrm{Cl}=$ confidence interval

\section{Spatial analysis}

Figure 1 shows the result of a map of ARI case distribution in toddlers based on patient location. Buffering in the working area of Puskesmas Imogiri I Bantul is shown by black circles containing green dots. The spread of non-pneumonia ARI cases in toddlers is clustered at various locations around the Imogiri market (red pentagons). This pattern indicated that the market was a risky place for contracting ARI both inside and outside the market community. In addition, ARI cases also spread evenly around the working area of Puskesmas, especially in Karang Talun, Imogiri, and Wukirsari. The fewest cases were found in Girirejo.
Buffer analysis was done to identify areas around geographical features. For example, Figure 1 is a boundary area of $100 \mathrm{~m}$. In this picture, many buffers that intersected (coincided) were compared with those that did not intersect with other ARI cases. This means there were indications that people with ARI transmit viruses to each other. The more buffers that intersect indicate an increased number of risk factors for ARI.

A spatial cluster shows a positive spatial autocorrelation when similar values are spatially clustered together. On the opposite side, the distribution has similar values but are separated/ 
Table 3. The distribution of ARI cases based on the history of ARI

\begin{tabular}{|c|c|c|c|c|c|c|}
\hline & $\begin{array}{c}\text { ARI } \\
n(\%),(n=170)\end{array}$ & $\begin{array}{c}\text { No ARI } \\
n(\%),(n=170)\end{array}$ & $\lambda^{2}$ & OR & $95 \% \mathrm{Cl}$ & $p$ \\
\hline \multicolumn{7}{|c|}{ Cough and cold in the last 1 year } \\
\hline Yes & $164(96.47)$ & $108(63.53)$ & 57.647 & 15.691 & $6.558-37.546$ & $<0.001$ \\
\hline No & $6(3.53)$ & $62(36.47)$ & & & & \\
\hline \multicolumn{7}{|c|}{ Cough and cold lasting over 2 weeks } \\
\hline Yes & $42(24.71)$ & $8(4.71)$ & 27.106 & 6.645 & $3.013-14.652$ & $<0.001$ \\
\hline No & $128(75.29)$ & $162(95.29)$ & & & & \\
\hline \multicolumn{7}{|c|}{ Exclusive breastfeeding } \\
\hline Yes & $16(9.41)$ & 9 (5.29) & 2.116 & 0.538 & $0.231-1.254$ & 0.146 \\
\hline No & $154(90.59)$ & $161(94.71)$ & & & & \\
\hline \multicolumn{7}{|c|}{ Immunization completeness } \\
\hline Complete & $8(4.71)$ & $6(3.53)$ & 0.298 & 0.741 & $0.251-2.183$ & 0.585 \\
\hline Incomplete & $162(95.29)$ & $164(96.47)$ & & & & \\
\hline
\end{tabular}

$\mathrm{ARI}=$ acute respiratory infection; $\mathrm{OR}=\mathrm{odds}$ ratio; $\mathrm{Cl}=$ confidence interval

Figure 1. A map of acute respiratory infection case distribution in toddlers based on patient location

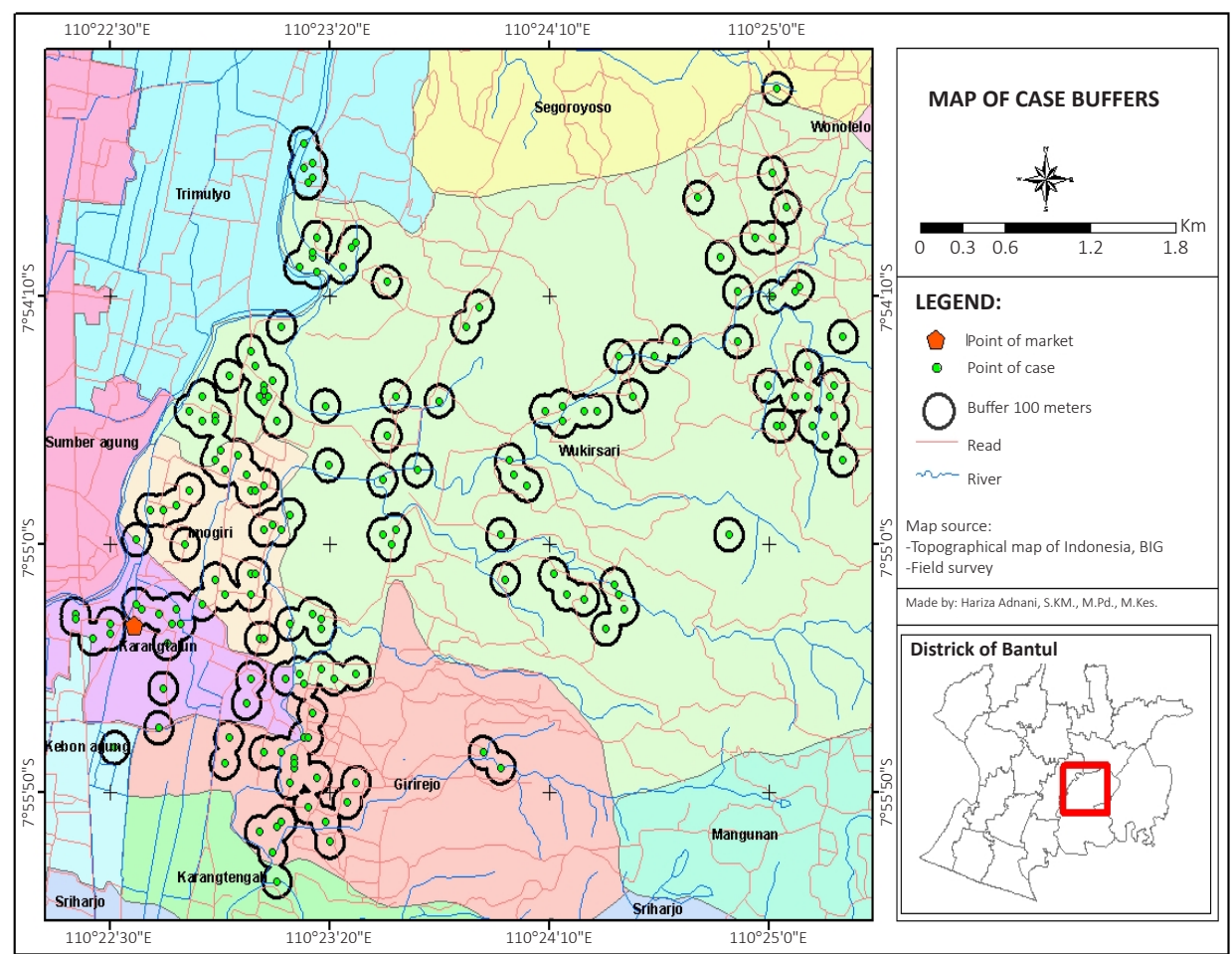

ARI is a disease that tends to cause clustering. Clustering occurs because most ARI sufferers tend to live in groups with individuals at risk of ARI so that increases the risk of ARI. This grouping makes it possible to detect differences in the incidence of cases between geographical locations.

Based on the coordinate distribution of cases, spatial clusters are made using the automatic correlation Index method that produces cluster analysis as in Figure 2. The conclusion is that case distribution occurs in clusters. map according to the analysis and the specified model. 


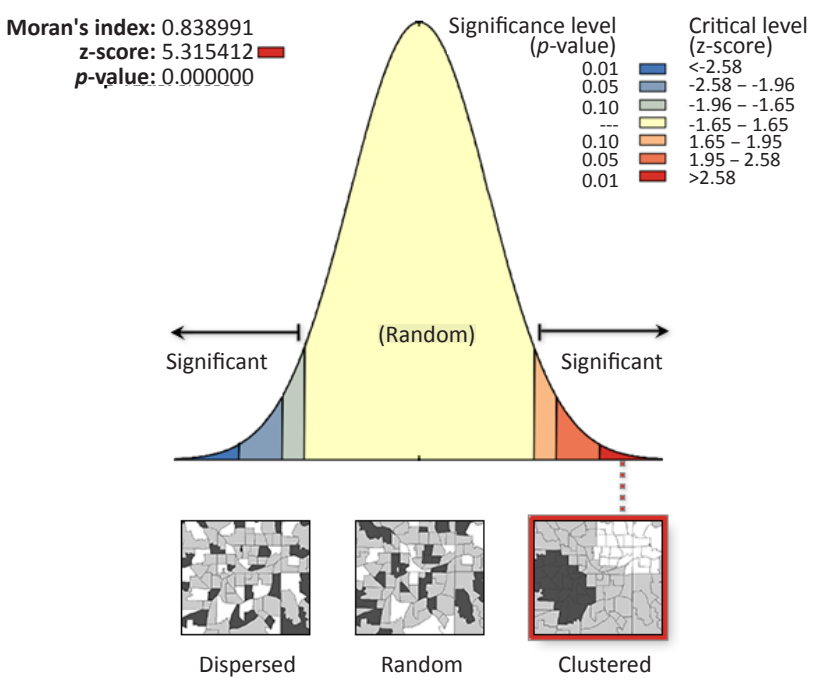

Figure 2. Moran's Index cluster

A case will occur in a cluster if the results of Moran's Index analysis indicate $p<0.1$. The results of cluster analysis, in this case, have a $p<0.1$ to produce a cluster. Based on the cluster results, it can be interpreted that the incidence of ARI cases in this region is interrelated or one case with another case is closely related because of its adjacent position. Moran's Index value $=0.838991$ shows positive spatial autocorrelation, but a small correlation because the value is close to 0 .

\section{DISCUSSION}

Based on the measurement results of the physical conditions of toddlers' rooms, there were some physical requirements for these rooms. Some rooms did not meet the requirements. Two requirements that were not fulfilled were room temperature and room lighting. They can be risk factors of ARI incidence in toddlers. The Regulation of Ministry of Health No. 1077/MENKES/PER/V/2011 regarding Guidelines for improving indoor air quality in the home state the physical requirements of a good room. A good room requires the temperature to be $18-30^{\circ} \mathrm{C}$ and lighting at a minimum of 60 lux. ${ }^{9}$ According to both Winslow and the American Public Health Association, the requirements of physiological needs of houses include lighting, ventilation, adequate space, and avoiding noise. The conditions of room humidity, room size, and ventilation size were mostly good (40-60\% RH and $\geq 1 / 10$ of the floor area).
The study results showed that there was a correlation between the history of $A R I$ and $A R I$ disease in toddlers, and two risk factors increased ARI incidence in toddlers. The two risk factors were cough and cold in the last one year, and cough and cold lasting over two weeks. The factors that reduced the risk of $A R I$ in toddlers were exclusive breastfeeding and complete immunization. The results of this study are in line with the study of Jackson et $\mathrm{al}^{10}$ that stated that the risk factors of ARI disease were a previous history of ARI, lack of exclusive breastfeeding, and incomplete immunization at one year. Dharmage et $\mathrm{al}^{11}$ stated that the risk factors for ARIs are the history of wheezing, and not being exclusively breastfed up to the completion of four months. In addition, breastfeeding is an important factor to prevent ARI. Azizi et $\mathrm{al}^{12}$ did not explain the exact duration of breastfeeding, but they only stated that breastfeeding should be for at least one month. The study by Deb stated that immunization played a protective role against pneumonia, breastfeeding pneumonia, and severe disease. ${ }^{13}$

The study results showed that there was a correlation between the variable of the house physical environment and ARI in toddlers. Risk factors increasing ARI incidence in toddlers were the room occupancy density, glass window on the house roof, electricity source, presence of smoking family members, and proximity to both pollution exposure and waste destruction. The results of this study are in line with the research of Dharmage et al ${ }^{11}$ stated that the risk factors for ARIs were passive smokers and sharing of sleeping space. The study of Tupasi et $\mathrm{al}^{14}$ stated that household crowding was associated with URI. The study of Azizi et $\mathrm{al}^{12}$ stated that home environment factors, especially crowding, could predispose to ARI, but air pollution was not a risk factor of ARI. In line with Azizi et al $^{12}$ the research of Deb stated that air pollution was not a risk factor of ARI. ${ }^{13}$ The study of Cardoso et $\mathrm{al}^{15}$ stated that the house density was a risk factor of respiratory infection, but sharing a bedroom with the child did not relate to respiratory illnesses. Gergen et $\mathrm{al}^{16}$ stated that environmental tobacco smoke contributed to the respiratory health of children aged two months to five years. Contaminated environments, mainly affected by cigarette smoke, were also a risk factor of respiratory infections. ${ }^{17}$ The risk factors of ARI were indoor air pollutants and crowding-more than seven persons per household, 
whereas parental smoking was also associated with ARI, but it was not significant. ${ }^{9}$ The risk factors of ARI were the social, economic, environmental, behavioral, and nutritional status. These included parents' education, settlement density, house type, house ventilation, illumination, and behaviors that produce an increasing amount of pollution in rooms such as smoking, and malnutrition. These are some of the factors contributing to the risks of ARI. In addition, the mother's breast milk also plays a role in the increase of respiratory tract diseases. ${ }^{6,18}$ The study of Jedrychowski et al ${ }^{19}$ stated that ETS increases the susceptibility of children to ARI and that central heating in the household was shown to have a protective effect when compared with children from households where coal or gas was used for home heating.

Ten factors reduced the risk of ARI in toddlers. They were permanent floor types, permanent walls, lighting, existence of a clean water source, closed and clean garbage dumps, septic tank distance over $10 \mathrm{~m}$, throwing the garbage in its place, a closed sewage channel, having an absorbing well, distance between the garbage dump and the clean water source over 10 $\mathrm{m}$. The results of this study are in line with the research results of Suriyasa et al. ${ }^{20}$ They found that non-dirt floors decreased ARI incidence by 51\% compared with dirt house floor. The research of Cardoso et al ${ }^{15}$ also supported that cases of respiratory illnesses would arise when the house did not meet the physical requirements (construction types, building materials, measurement of the floor area, wall height, windows, and solar orientation) and did not have adequate waste disposal.

\section{Conclusions}

The measurements of the physical conditions of the toddlers' rooms show that physical requirements that are not fulfilled are the room temperature and room lighting source. There is a correlation between the history of ARI and ARI in toddlers. Two risk factors increase the incidence of ARI in toddlers; they are cough and cold in the last one year and lasting for over two weeks. The factors that reduce the risk of ARI incidence in toddlers are exclusive breastfeeding and complete immunization. There is a correlation between the house physical environment and ARI disease in toddlers. Six risk factors increase ARI incidence in toddlers. They are the room occupancy density, glass window on the house roof, electricity source, presence of smoking family members, and proximity to both pollution exposure and waste destruction. Ten factors reduce the risk of $A R I$ in toddlers. They are permanent floor types, permanent walls, lighting, existence of a clean water source, closed and clean garbage dumps, a septic tank distance over $10 \mathrm{~m}$, throwing the garbage in its place, a closed sewage channel, having an absorbing well, and a distance between the garbage dump and clean water source over $10 \mathrm{~m}$. A pattern of ARI distribution can be seen because of the presence of location clustering of one patient to the other and the proximity of the patients' house to the market, road, or stream.

In conclusion, GIS produces a pattern of ARI distribution, the distance between patients, and the distance of the patient's house to the market, road, or river flow. Based on the cluster results, it can be interpreted that the occurrence of ARI cases in this region was interrelated or one case with another case was closely related because of their adjacent position.

\section{Conflict of Interest}

None of the authors entered as editorial board members or reviewers so that they were not involved in the review or decisionmaking process of the article. The authors state that this work was a case-control epidemiology study using primary data.

\section{Acknowledgment}

Acknowledgments to the Ministry of Research and Technology of Higher Education and STIKES Surya Global Yogyakarta who funded this research. Thanks to my promoter and co-promoter at the Graduate Programs in Health Promotion and Community Empowerment Universitas Sebelas Maret, Central Java, Indonesia, and my colleagues.

\section{Funding Sources}

The researchers were not funded by any pharmaceutical company, but funds were provided to them by the Indonesian government.

\section{REFERENCES}

1. Eric A. F. Simoes, Thomas Cherian, Jeffrey Chow, Sonbol A. Shahid-Salles, Ramanan Laxminarayan, and T. Jacob John. Disease Control Priorities in Developing Countries. $2^{\text {nd }}$ edition. New York: Oxford University Press; 2006.

2. WHO. Epidemic-prone \& pandemic-prone acute respiratory diseases: Infection prevention \& control in health-care facilities. Summary guidance 2007: 2008.

3. Ministry of Health RI. The Basic Health Research (Riskesdas) in 2013, Jakarta: Agency for Health Research and Development: 2013.

4. Zaman K, Baqui AH, Yunus M, Sack RB, Bateman OM, Chowdhury $H R$, et al. Acute respiratory infections in children: a communitybased longitudinal study in rural Bangladesh. J Trop Pediatr. 1997:43(3); 133-7.

5. King S, Glanville J, Sanders ME, Fitzgerald A, Varley D. Effectiveness of probiotics on the duration of illness in healthy 
children and adults who develop common acute respiratory infectious conditions: a systematic review and meta-analysis. $\mathrm{Br}$ J Nutr. 2014:112(1); 41-54.

6. Creswel WJ. 2002. Research Design Qualitative, Quanitative, and Mixed Methods Approaches, Second Edition. London; Sage Publication: 2002.

7. Boots, BN and Getis, A,. Poin Patern Analysis. Newbury Park, Ca: Sage Production: 1988.

8. Jacquez, GM. Spatial Cluster Analysis. Chapter 22. In The Handbook of Geographic Information Science. S. Fotheringham and J. Wilson (Eds.). Blackwell Publishing, 2008. p 395-416.

9. Ministry of Health RI, 2011. Decree of the Minister of Health of the Republic of Indonesia Number: 1077/MENKES/PER/V/2011 regarding Guidelines for Improving Indoor Air.

10. Jackson S, Mathews KH, Pulanic D, Falconer R, Rudan I, Campbell $\mathrm{H}$, et al. Risk factors for severe acute lower respiratory infection in children: a systematic review and meta-analysis. Croat Med J. 2013;54(2):110-21.

11. Dharmage SC, Rajapaksa LC, Fernando DN. Risk factors of acute lower respiratory tract infections in children under five years of age. Southeast Asian J Trop Med Public Health. 1996;27(1):107-10.

12. Azizi BH, Zulkifli HI, Kasim MS. Protective and risk factors for acute respiratory infections in hospitalized urban Malaysian children: a case-control study. Southeast Asian J Trop Med Public Health. 1995;26(2):280-5.

13. Deb SK. Acute respiratory disease survey in Tripura in case of children below five years of age. J Indian Med Assoc. 1998;96(4):111-6.
14. Tupasi TE, de Leon LE, Lupisan S, Torres CU, Leonor ZA, Sunico $E S$, et al. Patterns of acute respiratory tract infection in children: a longitudinal study in a depressed community in Metro Manila. Rev Infect Dis. 1990:12 Suppl 8:S940-9.

15. Cardoso MR, Cousens SN, de Góes Siqueira LF, Alves FM, D'Angelo LA. Crowding: risk factor or protective factor for lower respiratory disease in young children?. BMC Public Health. 2004;4:19.

16. Gergen PJ, Fowler JA, Maurer KR, Davis WW, Overpeck MD. The burden of environmental tobacco smoke exposure on the respiratory health of children 2 months through 5 years of age in the United States: Third National Health and Nutrition Examination Survey, 1988 to 1994. Pediatrics. 1998;101(2): E8.

17. Cerqueiro MC, Murtagh P, Halac A, Avila M, Weissenbacher M. Epidemiologic risk factors for children with acute lower respiratory tract infection in Buenos Aires, Argentina: a matched case-control study. Rev Infect Dis. 1990;12 Suppl 8:S1021-8.

18. Biswas A, Biswas R, Manna B, Dutta K. Risk factors of acute respiratory infections in underfives of urban slum community. Indian J Public Health. 1994;43(2):73-5.

19. Jedrychowski W, Maugeri U, Flak E, Mroz E, Bianchi I. Predisposition to acute respiratory infections among overweight preadolescent children: an epidemiologic study in Poland. Public Health. 1998;112(3):189-95.

20. Suriyasa P, Balgis, Sapton R, Hapsari MI. Non-dirt house floor and the stimulant of environmental health decreased the risk Acute Respiratory Infection (ARI). Med J Indones. 2006;15(1):60-5. 